only 13.5 days. The pain caused by a colution of thls strength is not excessive, and only in one $\mathrm{cr}$ two instances did patients complain of it.

Farther details of this serles of cases'are given in Table VIII.

In the examination of many of the films numerous cocci could be seen atter the diplobacilli had disappeared, so that zinc sulphate seems to have a specific action on the Morax-Axenfeldt diplobacillus.

While these observations were being made we recelved a small quantity of a new preparation called "nizin" which is a sulphanilide of zinc. Five czses of "MoraxAxenfeldt conjunctivitis " were treated with a 6 grains to the ounce solution, but af ter continuing the treatment for a month the bacilli could still be seen in the smears. We conclude that protargol and argyrol are not beneficial in this condition, but that zinc sulphate quickly cures the disease, and that the most brilliant results are obtained with an 8 grains to the ounce solution.

Batler, ${ }^{9}$ in descrlbing his experience with this disesse in Jerusalem says. "I do not think that in Palestine a wesker solution of zinc sulphate than 1 per cent. is of much use, and I have used 2 per cent. with great advantage."

A woman, aged 48, consulted Dr. Fergus at his clinic in December 1906. She had subacate conjunctivitis in both eyes, of about four weeks' duration. Her doctor had treated her with protargol used as drops night and morning. Her condition became more troublesome, and when she came to the Ey Infirmary her conjanctivae were deeply injocted, and somewhat swollen. A Dacteriological examination was made. and the Morax-Axenfeldt bacillus was found in great abundance. The protargol was stopped, and a solution of zine salphate ordered instead. In about three weeks her ejes had recovered.

As a case of acute conjunctivitis due to the MorazAxenfeldt bacillus cannot be diagnosed clinically trom \& case due to the Koch-Weeks bacillus a bacteriological examination is necessary. The above case shows the necessity of making such an examination belore beginning treatment.

One cannot but agree with the opinion expressed by Dr. Fergus ${ }^{10}$ that in an ophthalmic clinic an oil immes sion lens is just as necessary a part of the apparatus for diagnosis as is the ophthalmoscope.

Gonorrhotal Ophthatmia.

We have not had a sufficient number of cases of conjunctivitis due to the gonococcus to allow of a thorough investigation of the therspentic value of the organic preparations of silver. In some of the recent textbooks of surgery we are informed that the proper treatment for a tresh attack of urethral gonorrhoss is to cause an abundant diuresis by glving plenty of bland fluids and so wash out the urethra frequently, and, further, that no local treatment is necessary. 11

We treated gonococcal infections of the conjunctival sac on the same principles. The mothers were given normal sallne solution as a lotion, and were told to bathe the eyes every half-hour. Then twice daily we irrigeted the conjanctival sac with 2 pints of normal saline solution. In 5 cases we had under treatment irrigation was performed in the right eyes, and bathing with normal saline lotion and instillations twice daily with 20 per cent. solutions of arggrol were used for the left eye. In all of the cases both eyes were equally affected.

When irrigation was done only once a day both eyes made the same progress, but when the irrigation was performed morning and evening the irrigated eye recovered more rapldly. In performing irrigation we nzed a siphon tube of soft rubber with a glass nozzle. When the water had a fall of $2 \mathrm{ft}$, the cases did not seem to do so well, possibly because the force of the water opened up the inflamed tissues, and so lacllitated the entrance of organisms. The best results were obtained when the water had a fall of $1 \mathrm{ft}$. only, and that pressure of water was quite enough to permit of the thorough cleansing of the conjunctival gac.

Our experience thus leads us to think that gonorrhoeal ophthalmia in infants would be best treated by irrigating the conjunctival sac every two or three hours with 2 pints of normal saline solution at a pressure of $1 \mathrm{ft}$. of water.

Btaphylococoio and Streptococoic Conjunctivitis.

Conjunctivitis due to the Staphylococcus pyogenes albus and aureus, and to the Streptococcus brevis and longus is not

a very common condition. Poulard saw only 9 cases in two and a half years, ${ }^{12}$ and Inglis Pollock in an examination of 362 found only 8 due to the staphylococci..3

We have had only 4 cases, and these were treated by irrlgation in one eye, and by instillations of a 20 per cent. solution of argyrol in the other. The irrigated eses Improved more rapidly than did those treated with argyrol. The following case is worthy of note:


days durstion. The bulbar and palpebral conjunctiva was swollen and injected. The ejelids were oedematous. In the smear numerous groups of staphylococcl were found. Irrigation with normal saline solution was done every morning, and the mother was told to bathe the eyes every hour with (normal saline) lotion. After the treatment had been continued for seven days the discharge had disappeared, and an agar-agar tube was inoculated from the conjunctival sac with gegative result.

The eyes treated with argyrol were three or four days later in becoming cured of the condition, but the argyrol lessened the discomfort and blepharospasm.

I have pleasure in acknowledging my great indebtedness to Dr. Fergus, who gave me every possible facility for making full use of the large amount of material at his cllnic. I have also to thank Dr. Inglis Pollock for the liberty of working in the Pathological Laboratory of the Glaggow Eye Infirmary.

1 Trans. Am. Ophth. Soc., vol. ii, part 1. p. 51. 2 Marshall and Neave, 1Trans. Am. Ophth. Soc., vol. 1i, part 1, p. 51.2 Marshall and Neave, Ophth Soc. vol it pourt 1, p. 2L. \& Bishop Harman, The Conjunctiva in Health and Disease p. 107 5 stephenson. Contagious Ophthalmia p. 61 6 Ge Schweinitz, Trans. Am. Ophth. Soc., iso6. 7 T Stevens, Ophth. Record Iuly, 1906, p. 354. 88tephenson, Lancet, June 6th, 1897. 9 Butler, Th Royal London Ophth. Bosp. Reports, vol.xvii, part 1, March, 1907, p. 115 10 Fergus, Edinburgh Medical Journal, February, 1906, $p$. 106. 11 Ros and Carless, Manual of Surgery, 6th edition. p. 131. 13 Poulard, Archives donjunctivitisie, Ootober, 1505.' 18 Inglis Pollock, The Bacteriology of

\title{
AN INVESTIGATION
}

INTO THE

\section{FREQUENCY AND SIGNIFICANCE OF OPTIC} NEURITIS AND OTHER VASCULAR CHANGES

IN THE RETINAE OF PATIENTS SUFFERING FROM PURULENT DISEASE OF THE

\section{MIDDLE EAR,*}

WITH THE RESULTS OF THE EXAMINATION OF THE RYES AND EARS IN 100 OONSECUTIVE CASHS.

\section{J. STODDART BARR, and JOHN ROWAN,}

M.B., CH.B.,

ASSISTANT SURGRON, GLASGOW OPHTHALMIC SURGEON. GLASGOW HOSPITAL FOR DISEASES OF THE ROYAL INFIRMARY : OPHTHALMIC FAR, NOSE, AND THROAT; S SURGEON, GLASGOW HOSPITAL GXTRA DISPENAARY SURGEON, FOR DISEASES OF THE FAR, NOSE,

Is entering upon this investigation, our objects were to determine (1) whether the condition known as optic neuritis occurs with any frequency in cases of simple purulent otitis media, where there is no evidence of intracranial or vascular complication; (2) whether, short of an actual optic neuritis, vascular changes in the fundus of the eye of a less marked character are common in such cases.

Already Politzer and Barker have referred to the occasional occurrence of optic neuritis in simple purulent ear disease, and Tenzer and Espenschied have recently reported on its frequency in cases of otitic intracranial complications, and also mentlon that vascular changes of a minor character sometimes occur in uncomplicated cases, passing away, however, with the cessation of the active aural mischief. No systematic examination, however, seems hitherto to have been made to determine the frequency of these changes.

The 100 cases, which were all cases of purulent otitis media, mostly of the chronic variety, were taken consecutively without selection, the examination of the eyes either immediately preceding or following that of the ears.

* Bead before the Glasgow Medico-Chirurgical Society, October 18th, 1907. 
The aural examination included: (1) A brief history of the ear affection; (2) the testing of the hearing distance by a watch normally heard 36 in. off ; (3) the application of Rinne's and Weber's te:ts, when the age of the patient permitted, a tuning-fork of about 300 vibrations being used; (4) the state of the middle ear, especially the tympanic membrane and tympanic cavity, noting carefally such polnts as the presence and situation of a perforation, the amount and character of the discharge, the presence or absence of granulation tissue or of cholesteatomats. The results of this examination are given in Table I, to which we refer you. A second and third examination of many of the patients were made at intervals of several months with the object of com. paring the condltions with those seen at the first examination.

The examination of the eyes was conducted in the following manner: Patients with an abvlous eye condition, such as leucomata, cataract, etc., were excluded. For the distant vision Snellen's, and for near vision Jaeger's well-known test types were ured; then the refraction was noted by the shadow test, and this checked by direct estimation. In this way many low degrees of ametropia were noted, when for all practical purposes the eyes might have been passed as emmetropic. The eye movements and the responses to light and accommodstion were carefully noted. The ophthalmoscoplc examination was always made without the examiner having any idea whether one ear only or both were affected, so that an unprejudiced examination might be made.

The second and third examinations were also made on the same basis, with the addition that the improvement or otherwise of the ear condition was not mentioned till the ophthalmoscople examination was completed. Cases with errors of refraction were not excluded, as to exclude them might have interfered with the sequence of cases.

By this means the examination of the eyes was quite independent of that of the ears, and so was made entirely "without prejudice."

Dr. Rowan having last year examined the eyes of 500 school children (that is, 1,000 ey es), was thus able to compare these results with those of our 100 cases, and was much struck with the greater frequency with which vascular changes occurred in the Jater series. This result is all the more striking, as one naturally expects to find vascular changes more frequently in children who are straining their eyes at school than in a series of cases whlch includes adults as well as children.

The records of these examinations are preserved in a tabulated form, but smaller tables have been prepared, so that the results may be presented in a simpler and briefer way.
I.

As regards the first aim of our investigation-that is, to ascertain the frequency of optic neuritis in simple uncomplicated paralent ear disease-at our first examination optic neuritis was found, in a pretty well defined form, in 4. Of these, 2 did not, unfortunately, appear for further observation, although one of them was an acute case and had symptoms suggestive of mastoid empyema. The other 2, which were followed up, were examined more than once; one of them showed at the second examination, four months later, a slightly more marked change in the eyes, with no improvement in the state of the ear; the other came nltimately to the radical operation, and when examined some weeks after the operation the neuritis was beginning to pass off. In addition to these 4 cases observed at the first examination, 2 were found at the second examination to have developed optic neuritis; one of these was eventually operated upon after having suddenly developed urgent symptoms, and an extradural abscess was discovered over the sinus, after which the optic neuritis began to pass off.* In the other case the ear condition showed no improvement, while frontal headache, which had been long complained of, had become lately much more frequent and severe.

\section{II.}

The second object of our investigation was to determine if vascular changes in the fundus, short of optic neuritls, were found in puralent middle-ear disease with any frequency. This, we consider, yielded results of some importance. These changes, which we have termed vascular engorgement, include fullness, and, in many cases, tortuosity of the veins, with, in other cases, a somewhat full and pinklsh optic disc.

In deciding as to the value to be attached to these changes we divided the cases into two groups: (1) Cases in wh!ch both eyes, for all practical purposes, had normal refraction (that 1s, were emmetropic) - these numbered 54 and (2) those in which there were errors of refraction (that is, ametropic) of varying degrees in one or both eyesthese numbered 46. In Table III you will find in Class I the results of the first eye examination, including the whole 100 cases. In Class II you will find the results in 60 , which were examined a second time, and you will also find the results compared with the first examination not only of the eye but of the $\epsilon$ ar. Class III gives the results of $\&$ third examination, including 22 of these 60 cases, where also a compariscn is made with previous eye and ear examinations.

* October 18th, 1907. Ontic neuritis completely passed off; vision perfect in both eyes-that is, $\frac{6}{8}$ and J.1; mastoid cavity quite dry.

Table I.-Results of the Examinations of the Fias of 100 Patiknts.



Tarle II.-Regraction of the 100 Cases.

Examination of 200 Eyes: 108 Emmetropic (Both Eyes), 3 (One Eys).

The Refraction of the Ametropic Eyes was as follows:

\begin{tabular}{|c|c|c|c|c|c|c|c|c|}
\hline Hyperm. & Hyperm. Astig. & Myop. & Myop. Astig. & Mixed $\Delta$ stig. & $\begin{array}{l}\text { Refraction not } \\
\text { Stated. }\end{array}$ & $\begin{array}{l}\text { Emmetropic } \\
\text { Ametropic } \ldots \\
\text { Not given } \ldots\end{array}$ & $\begin{array}{l}\ldots .0 \\
\ldots\end{array}$ & $\begin{array}{l}\ldots \\
\ldots \\
\ldots\end{array}$ \\
\hline 26 & 27 & 10 & 5 & 19 & 2, i.e., one case & Total & $\cdots$ & $\ldots 200$ \\
\hline
\end{tabular}


TABLA III.

Ctass I:-100. Cases. Result of First Eye Examination.

\begin{tabular}{|c|c|c|c|c|c|}
\hline $\begin{array}{l}\text { Division I-Emmetropics } \\
\text { Division } 1 \text { - Em-Ametropics. }\end{array}$ & $\cdots$ & $\ddot{*}$ & $\cdots \frac{54}{100}$ & $\begin{array}{c}\text { Number showing vascular changes :- } \\
39, \text { or } 72: 2 \text { per cent. } \\
33, \text { or } 71.7 \text { fer cent. } \\
\overline{72}\end{array}$ & $\begin{array}{l}\underset{15}{\text { Normal. }} \\
\frac{13}{88}\end{array}$ \\
\hline
\end{tabular}

Class II:-60, Cases. Examined Fwice (Ears and Eyes).

\begin{tabular}{|c|c|c|c|c|c|}
\hline & & Normal. & $\begin{array}{l}\text { 1st_Exam. of Eyes } \\
\text { (Vascular changes). }\end{array}$ & 2nd Exam. of Eyes. & 2nd. Exam. of Ears. \\
\hline Disision L-Fmmetropigs & 34. & 7 & 27 & $\begin{array}{l}14 \text { unchanged } \\
2 \text { improved } \\
11, \text { worse }\end{array}$ &  \\
\hline Division II.-Ametropics & $\begin{array}{l}26 \\
- \\
60\end{array}$ & $\begin{array}{l}6 \\
- \\
13\end{array}$ & $\begin{array}{l}2 c \\
- \\
47\end{array}$ & $\begin{array}{l}13 \text { unchanged } \\
\text { 4.jmproved } \\
\text { 3.worse }\end{array}$ & $\left\{\begin{array}{l}9 \text { unchanged or worse } \\
4 \text { improved. } \\
2 \text { improved. } \\
\text { h unchanged. } \\
3 \text { unchanged or worse. }\end{array}\right.$ \\
\hline
\end{tabular}

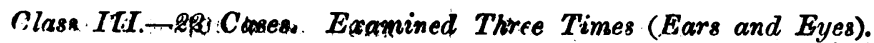

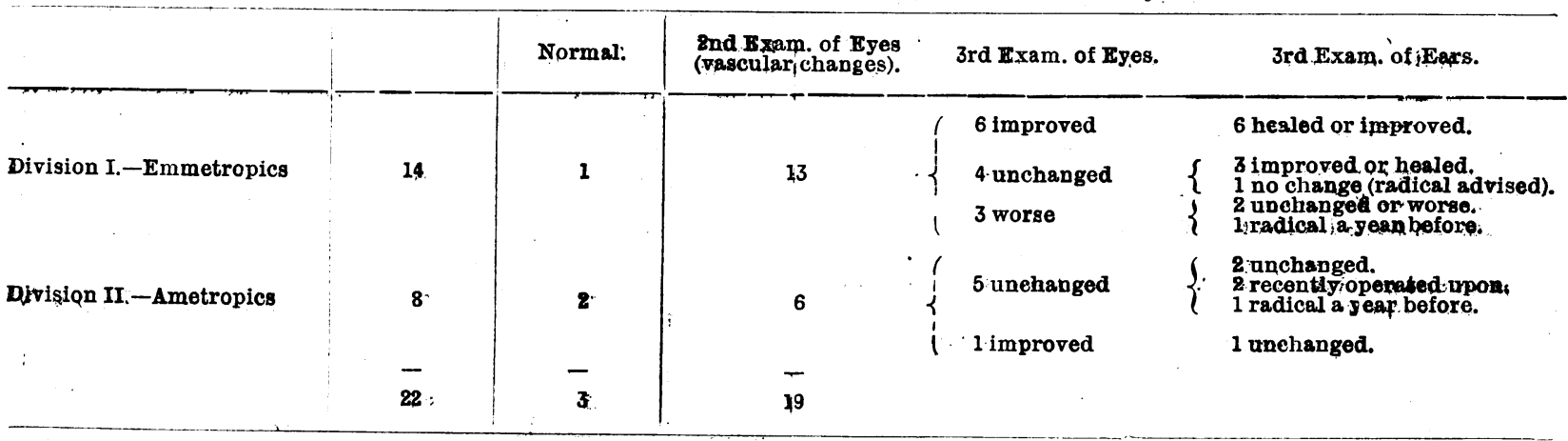

TABLE IV.

A. mCases shaming i-tinct raschls $r$ engorgement at the 20

B.-Cases showing-normat fundi-at-1 stritamination:
Progress of the Ear condition subsequent ta the lstullamination;

$\{16 \%$ hea]ed or improved.

ched required malost.

$\{81.5 \%$ healed or much improved:

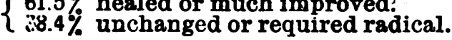

NOTE. - In 40 per cent. of the 38.4 per cent. the treatment was completely neglected.

TABLE V.

EYq.

Condition of the fundi at the 2nd Examingtion compared with the condition of the lst rximination:

27.unchanged.

6 improved.

14 worse.

Of the 100 cases 72 , including the cases of actual optic apuritts previously referred to, showed more or less vascular engorgement in one or both lundi, generally in both. These were about equally divided between the emmetropics and the ametropics, which is a rather striking circumstance, and' suggests a common caure to be looked for outside the eyes. Because, if errors of refraction accounted for these changes, one would have expected: a much higher percentage in the ametropic eses than in the emmetropic. In many of these 72 cases, changes were so comparatively slight that it was thought right, after careitul scruting, to ellminate a considerable npmber, especially of the ametroples; and they were thps pduced to 27-23belonging to the emm they were thus emetropics. These showed vascular engorgement of the fundus which, in the opinion of Dr: Rowan, could not

\section{EAR.}

Progress af the Ear oondition as shown at the 2nd Examination:

$$
\begin{aligned}
& \left\{\begin{array}{l}
19 \text { unchanged or worse. } \\
8 \text { impraved an healed }
\end{array}\right. \\
& \{3 \text { improved or healed. } \\
& 12 \text { unchapged or worse: } \\
& 2 \text { improved }
\end{aligned}
$$

possibly ,beaceounted for by errors of refraction on brepo strain. It will be noticed that on]y.4 cases ont of the 46 ametropics are included in the list; but, as a matter of fact, there were many mare presenting changes which were suspicious yet not considered sufficiently pronounced to be included, taking into conisideration their errors in refraction. Of these 27 cases we were only able to follow-the course of 20 , as 7 of them were lost sight of.

There, were, therefore, in the 100 cases 6 which showed vascular changes in the fundus amounting to pretty velldefined optic neuritis, and 21 showing vascular chang.es which, while short of what might be termedi optic neuritis, were not compatible:with the normal condition.

What is the significance of these changea? Let us take the 20 cases showing undoubted engorgement of the fundus, and compare the progress of the ear conditions 
With that of 13 casesiwhich at the first eye examination dhowedinormal fandi. In only 15 per cent. oft the 20 cases had the ear condition recovered or showed distinct improvement after several months of conservative treatment, while the remainder showed no improvement, and, Indeed, half of them ultimately came to the radical operation. On the other hand, of the 13 cases showing normal fundi at the first examination, in 61.5 per cent, as compared with 15 per cent, in the 20 cases, the ears were found after some months of conservative treatment practically healed and dry, while the remainder showed noilmprovement. These facts seem to indicate as far as they go that in those cases where vascular engorgement was found at the first examination the purulent ear disease was of a specially virulent character. This is strongly emphasized by the fact that, out of 12 which vequired the radical mastoid operation, 10 showed vascular angorgement or distinct optic neurltis. Another instance of the significance of vascular engorgement is shown in one of the cases where the vascular changes were distinct through not amounting to actual optlc neuritis. In this case the radical operation was carried out a few days after the eye examination, and three or four weeks later purulent leptc-meningitis developed with a fatal ending.

It is right to say that two of our cases showed normal frnid at : the first examination, but at the second they gave indications of slight vascular engorgement, although complete cessation of the ear discharge had taken place in both under ordinary treatment. We have, so far, no satisfactory explanation of these two rather anomalous cases.

While the number of cases here dealt with is acarcely sufficient upon which to base dogmatic conclusions, it cannot be said that the Inquiry has been unfruitfal. It kat shown (1) that vascular changes in the fundus of the eye are far from being uncommon in puralent disease of thermiddle ear, that in 6 out of the 100 there was optic reuritis, and in 21 there were vascular changes, abnormal inicharacter, buttshort of optic neuritis; (2) that the ear dffections associated with these vascular changes in the ere were specially severe and persistent, as shown by their course, compared with others; (3) that, therefore, the presence of these vascular changes in the optic discs would seem to give an unfavourable charaoter to the prognosis of purulent middle-ear disease-in short, it is 8 danger signal not to be ignored. The practical lessons deducible from these are (1) that a case showing these dhanges in the fundus should be closely watched, "and thalrexistence should be regarded an an additional reason for the early performance of the radical 'mastoid opera tion; (2)!if; on the other hand, they show a tendency to olear off, especially with improvement in the ear condition, or if the fundus is normal to begin with and remalns: so, we may with more confidence look for a favourable response to conservative treatment.

Theme are other important points in connexion with these examinations, such as the ages of the patients, the average duration of the purulent disease, the condition of the air in redation to the bone condnction, as well as the probable rationale of the vascular changes in the fundus. These may, however, fall to be considered on a future Oreasion.

iIn conclusion, we beg to express the hope that this linited investigation and its results may stimulate the crieral use of the ophthalmoscope in cases of purulent divease of the middle ear.

A vacoination institute has been established at Seoul in Gorea; and is already in active work.

: Nirc a meeting of the supporters of the National Hospital for the Paralysed and Epileptic, Queen Square, on Tovember 19th, it was decided to take steps at once to rajse a.sum of some $£ 10,000$ in antioipation of the jubilee of the linatitution two years hence. It is desired to commemorate the occasion by making certain. structural alterations in therexisting buildings. These have long been geen to be necessary, and will: not increase the general expenditure on maintenance. The out-patien't department is too small the attetidances now being over 40,000 a year, and the gemmodation for nurses 'is unsatisfactory. A new lift attila phydicaliexercise'room are also required. The land nowestary for'the'extension is already in the possession of thothospital, and if the money were in hand the building could be commenced forthwith
BEVENTY-FIFTH ANNUAC MEETING

OF THI

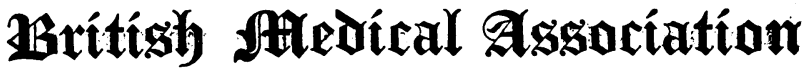

Held at Exeter, July $27 t h$, 29th, s0th, and 31st, and August 1st and 2nd, 1907.

PROCEEDINGS OF BECTIONB.

\section{SECTION OF DENTAL SURGERY.}

JoHn McKno Ackland, M.R.C.S., L.D.S.Eng., President

\section{PRESIDENT'S INTRODUCTORY REMARKS.}

\section{THE RELATION OF DENTAL SURGERY TO} GEMERAL MEDICINE.

IT was with many misgivings that I accepted the position of President of this Section, following, as I do, men of such standing in our speciality; and, but for the fact that $I$ 'felt sure I could rely on your indulgence in betaring with my many shortcomings, I should not have been in this chailr to-day.

For many years I have held a strong opinion that a Section in Dental Surgery should be formed in connexion with our Association, and so long ago as February; 1889, I wrote a letter to the JodRNAL pointing this out, and at the same time referring to the fact that nearly all our international medical congresses had their dental and oral sections. The letter received considerable support from many members; on the other hand, some thought that it rather tended to divide the dental profession into those with and those without medical qualifications; but I maintain that the division, if it take, place at all, occune when a man belongs to the British Medical Association,


Section did not become an accomplished fact for some zears after-not until 1903-it came then at a most opportune time, in that it acted as a counterblast to the movement, then receiving some support, of separating dental surgery from the medical profession and placing it on its own foundation, whatever that may mean, for it seems to me impossible to sever it from medicine or surgeny as a whole.

There are more than a hundred members of our Assa ciation pratising dental surgery, and over 150 more men outside, but with qualifications: entitling them to join: and that dental surgery is a branch, and $a \cdot b y$ no means unimportant branch, of the healing art.is being more.and more recognized.

This is but the third meeting at which our Section has been held, and it is only necessary to glance at the records of the other two to see how very distinctly our speciality. has established its claim to a section.

Dr. William Hunter, Mr. Rickman Godlee, and Mr. Edmund Owen have each of them demonstrated the close relation of oral pathology to questions that at first sight appear almost incredible. It is in the field of pathology that thase who treat the body and those who have oharge of one of its cavities meet on the common ground at scientific interest, and it is as important for those who treat the part to be cognisant of the whole as for those who treat the whole tor possess a knowledge of the pathology of each part.

The teeth are lbving portions of the bods; , composed of highly-differentiated: tissues, and are in intimate, relation ship with thervascular, nenvous, and lymphatic sprstems. They share in a special manner with the well hbeing of the whale as well .as in its digeases. It necessarily followis 